\title{
Fibroblast Growth Factor-2 Protects Entorhinal Layer II Glutamatergic Neurons from Axotomy-Induced Death
}

\author{
Daniel A. Peterson, Carrie A. Lucidi-Phillipi, Douglas P. Murphy, Jasodhara Ray, and Fred H. Gage \\ Laboratory of Genetics, The Salk Institute, La Jolla, California 92037
}

The entorhinal cortex is a major relay between the hippocampus and other cortical and subcortical regions. Glutamatergic axons from layer II neurons form the entorhinal cortical projection to the hippocampus via the perforant pathway. We have demonstrated previously that lesion of the perforant pathway causes the death of $\sim 30 \%$ of entorhinal layer II (ECL2) neurons. To elucidate mechanisms contributing to neuronal death and to investigate strategies preventing it, we identified the phenotype of the vulnerable neuronal population. Sections were immunolabeled with antibodies to the neuronal markers NeuN, glutamate, and calbindin- $D_{28 \mathrm{k}}$, and to receptors for fibroblast growth factor-2 (FGFR1) and NMDA (NMDAR1) and were examined using confocal microscopy. Calbindin immunoreactivity was strikingly lamina-specific to ECL2, where one-third of all ECL2 neurons were calbindin-positive. Localization of glutamate revealed that half of the glutamatergic ECL2 neurons coexpressed calbindin. Quantification using unbiased stereology at

The entorhinal cortex is a crucial relay providing a wide range of cortical input to the hippocampus and providing the hippocampus with an outlet for processed information to the cortical mantle. The principal entorhinal input to the hippocampus comes from glutamatergic projection neurons from entorhinal cortex layer II (ECL2) that, along with input from layer III neurons, travel via a major fiber tract, the perforant pathway (Fig. 1). Entorhinalhippocampal circuitry has been widely studied with respect to both anatomical (Witter, 1993) and functional (Jones, 1993) connections. The entorhinal cortex has been hypothesized to play a functional role in organization and processing of learning and memory both at a systems level (Levisohn and Isacson, 1991; Wiig and Bilkey, 1994) and at the cellular level via long-tern potentiation (LTP) (Bliss and Lømo, 1973; Abraham et al., 1993). However, the entorhinal cortex appears to be particularly vulnerable to neurodegenerative and neuropathological insults, including epilepsy (Du and Schwarcz, 1992; Heinemann et al., 1993), Alzheimer's disease (Hyman et al., 1984, 1986; Armstrong et al., 1994), and Parkinson's and Huntington's diseases (Braak and Braak, 1992). The entorhinal cortex also demonstrates developmental

Received Aug. 21, 1995; revised Oct. 20, 1995 ; aceepted Oct. 23, 1995.

This work was supported by National Institute of Neurological Discases and Stroke Grant P01-NS28121. We thank Steve Forbes, Chung Ho, and John Leppert for technical assistance. We also thank the reviewers for their comments on this manuscript.

Correspondence should be addressed to Daniel A. Peterson, The Salk Institute (LOG), 10010 North Torrey Pines Ruad, La Jolla, CA 92037.

Dr. Murphy's current address: University of Colorado Health Sciences Center. Department of Psychiatry, 4200 East 9th Avenue, C-249, Denver, CO 80262.

Copyright (C) 1996 Society for Neuroscience $0270-6474 / 96 / 160886-13 \$ 05.00 / 0$
9 weeks after lesion of the perforant pathway revealed that the only ECL2 neuronal population that experienced a significant $(70 \%)$ loss $(20 \%$ of the total) was the population of glutamatergic ECL2 neurons that did not coexpress calbindin. All ECL2 neurons expressed FGFR1; therefore, we tested the role of FGF-2 in the survival of glutamatergic ECL2 neurons. We grafted fibroblasts genetically engineered to express nerve growth factor or FGF-2 and found that only FGF-2 grafts prevented loss of the vulnerable glutamatergic/calbindin-negative neurons. We present a hypothesis for the selective vulnerability of these glutamatergic/calbindin-negative ECL2 neurons and address the role of FGF-2 in neuronal rescue.

Key words: calbindin; glutamate; trophic factors; fibroblast growth factor; neuronal death; neuroprotection; oxidative stress; calcium; excitotoxicity; Alzheimer's disease; ischemia; stereology

abnormalities correlated with schizophrenia (Falkai et al., 1988; Arnold et al., 1991; Jakob and Beckmann, 1994).

We have sought to model neuronal cell death in ECL2 neurons by transection of the perforant pathway, causing retrograde degeneration (Fig. 1). The perforant path lesion model makes it possible to investigate the specificity and mechanisms of the sequelae leading to neuronal cell death. With this knowledge, we plan to develop strategies to interrupt or prevent the degenerative process. In our first study (Peterson et al., 1994), we found that within 2 weeks after perforant pathway lesion, $\sim 30 \%$ of ECL2 neurons had died. However, these data could not reveal the phenotypic differences between those ECL2 neurons that survived and those that died because of the lesion.

Using the perforant path lesion model in the present study, we have discriminated the vulnerable population of neurons in ECL2 and have determined that these neurons, like all ECL2 neurons, express receptors to fibroblast growth factor-2 (FGFR1). We have used a discrete delivery system of FGF-2 to the injured axons and compared the effect of FGF-2 to that of nerve growth factor (NGF). Our results lead to this hypothesis: only a select population of axotomized neurons is vulnerable to neuronal cell death and FGF-2 can over-ride the axotomy-induced cascade of events that leads to death of the vulnerable population.

\section{MATERIALS AND METHODS}

Lesion and grafting. Female Fischer 344 rats were anesthetized with a mixture of ketamine $(75 \mathrm{mg} / \mathrm{kg}$ ), xylozine $(4 \mathrm{mg} / \mathrm{kg})$, and acepromazine $(5.6 \mathrm{mg} / \mathrm{kg})$ and placed in a Kopf stereotaxic framc, in which they received an aspirative right-unilateral perforant path lesion, as described previously (Peterson et al., 1994). The lesion cavity was filled either with hydrated Gelfoam (Upjohn, Kalamazoo, MI) as a control graft or with 

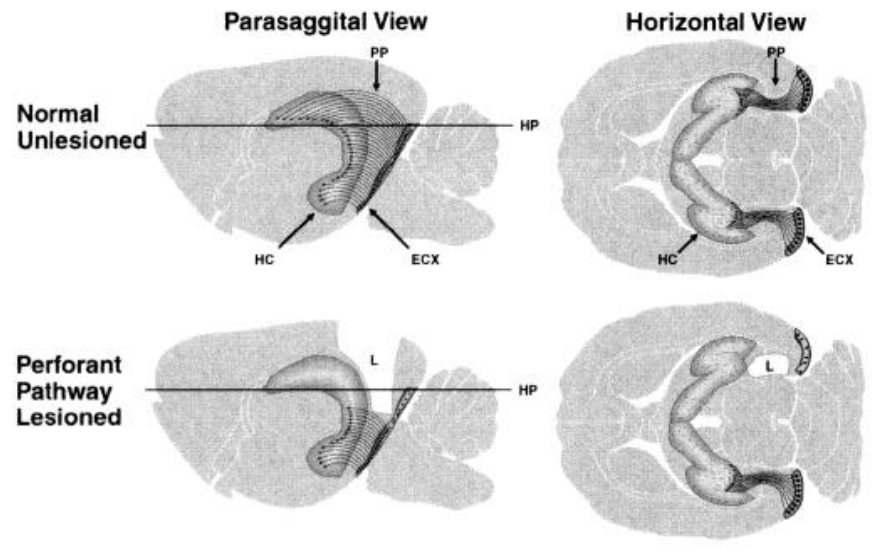

Figure 1. Schematic of the normal, unlesioned rat brain showing the anatomical relationship of the hippocampus $(H C)$ and the entorhinal cortex $(E C X)$. The cell bodies of entorhinal cortex layer II (ECL2) project to the hippocampus, forming a wide ribbon of fibers known as the perforant pathway $(P P)$. These structures are indicated in a projection of parasagittal planes of section with a horizontal plane of section $(H P)$ shown on the right. In the horizontal view, the entorhinal cortex $(E C X)$ occupies the caudal pole of the cerebral cortex, whereas the ECL2 projection fibers $(P P)$ follow a course medial to the splenium of the corpus callosum, passing through the subiculum, to innervate (primarily) the outer molecular layer of the dentate gyrus (part of $H C$ ). When a perforant path lesion $(L)$ is performed, the entorhinal-hippocampal fibers distal to the lesion cavity degenerate. The cell bodies of the projection neurons in ECL2 are damaged by the lesion, and a portion of them completely degenerated. The lesioned entorhinal-hippocampal anatomy viewed in the horizontal plane shows that only the right hemisphere receives an aspirative lesion $(L)$, leaving the left hemisphere to serve as an intact control. The lesion completely transects the perforant pathway, causing the degeneration of a population of the ECL2 neurons on the lesioned side. The lesion cavity provides a ready site into which trophic factorexpressing grafts can be placed both to supply trophic support to the injured ECL2 neurons and to provide a substrate for any regenerative growth back into the hippocampus.

one of three types of genetically engineered fibroblasts suspended in reconstituted collagen, as described below.

Skin biopsies were obtained from inbred Fischer 344 rats as described previously (Fisher et al., 1991). Primary fibroblasts were transfected with a transgene to express NGF (Rosenberg et al., 1988), basic FGF-2 in its native, membrane-associated form (FGF-2b) (Ray et al., 1995), or FGF-2 combined with a signal sequence that facilitated active secretion of the protein from the cell (FGF-2s) (Ray et al., 1995). Transfected fibroblasts were propagated in DMEM supplemented with $10 \%$ fetal bovine serum, $0.3 \mathrm{mg} / \mathrm{ml}(2 \mathrm{~mm})$ glutamate, $2.5 \mu \mathrm{g} / \mathrm{ml} \mathrm{amphotericin,} \mathrm{and} 40 \mathrm{mg} / \mathrm{ml}$ gentamycin in a $10 \% \mathrm{CO}_{2}$ incubator. After reaching $90 \%$ confluence, fibroblasts were washed with PBS, removed from the vessel substrate by trypsinization, and resuspended in DMEM. Cells were counted and seeded at a final concentration of 600,000 cells $/ \mathrm{ml}$ in $0.1 \%$ reconstituted type I collagen (Sigma, St. Louis, MO). Individual aliquots of the fibroblast-collagen mixture $(0.25 \mathrm{ml}$ or 150,000 cells $)$ were prepared separately in sterile conical Eppendorf tubes and placed in an incubator $(10 \%$ $\mathrm{CO}_{2}, 37^{\circ} \mathrm{C}$ ) for $24 \mathrm{hr}$. After $24 \mathrm{hr}$ in culture, timed to coincide with the day of surgery, the fibroblast-collagen mixture had constricted into a solid plug of an appropriate size and shape to fill the lesion cavity. Furthermore, each graft consisted of a standardized number of cells occupying an equivalent volume.

Histology. At 9 weeks after lesion/grafting, animals were perfused transcardially under deep anesthesia with a fixative mixture of $4 \%$ $p$-formaldehyde and $0.1 \%$ glutaraldehyde in $100 \mathrm{~mm}$ phosphate buffer. The brains were removed and post-fixed overnight in fixative. One brain from each group was vibratome-sectioned $(60 \mu \mathrm{m})$ in the horizontal plane, and the sections were stored in $100 \mathrm{~mm}$ phosphate buffer with $0.01 \%$ sodium azide at $4^{\circ} \mathrm{C}$. After equilibration in $30 \%$ sucrose, the remaining brains were sectioned $(50 \mu \mathrm{m})$ on a freezing-sliding microtome in the horizontal plane and the sections were stored in cryoprotectant (glycerol/ethylene glycol/phosphate buffer) at $-20^{\circ} \mathrm{C}$. A $1: 6$ series of tissue sections was mounted on gelatin-coated slides and Nissl-stained using $0.5 \%$ aqueous thionin.

Immunocytochemistry. Sections selected for immunocytochemistry were washed twice in $100 \mathrm{~mm}$ Tris-buffered saline (TBS), blocked for at least $1 \mathrm{hr}$ in TBS containing 5\% donkey serum (Jackson Immunoresearch, West Grove, PA) and $0.25 \%$ Triton X-100 (Sigma), and incubated with pooled primary antibodies diluted in TBS containing $0.25 \%$ Triton $\mathrm{X}-100\left(\mathrm{TBS}^{+}\right)$. After incubation, the sections were washed twice in the blocking solution and incubated with species-specific secondary antibodies conjugated to the desired fluorophores [donkey anti-species dichlorotriazinyl amino fluorescein (DTAF), Texas Red, or Cy3; Jackson Immunoresearch] diluted in $\mathrm{TBS}^{+}$for $2 \mathrm{hr}$ in the dark, then washed and mounted. For biotin-streptavidin amplification, sections were incubated for $2 \mathrm{hr}$ in biotinylated donkey anti-species antibody diluted in $\mathrm{TBS}^{+}$, washed twice in $\mathrm{TBS}^{+}$, incubated in streptavidin conjugated to the desired fluorophore (DTAF, Texas Red, or Cy3; Jackson Immunoresearch) diluted in $\mathrm{TBS}^{+}$for $2 \mathrm{hr}$ in the dark, and then washed and mounted. After brief air-drying, mounted sections were coverslipped with a $10 \%$ solution of polyvinyl alcohol (Air Products, Allentown, PA) containing 2.5\% 1,4-diazabicyclo-2,2,2-octane (Sigma). Primary antibodies used in this study were as follows: mouse anti-NeuN (gift of Dr. R. Mullen, University of Utah, Salt Lake City, UT) used at 1:10 with amplification; rabbit anti-calbindin- $\mathrm{D}_{28 \mathrm{k}}$ used at 1:1000 (Swant, Bellinzona, Switzerland); mouse anti-glutamate used at 1:100 (Incstar, Stillwater, MN); mouse anti-FGFR1 used at 1:25 with amplification (gift of Dr. A. Baird, Scripps Institute, La Jolla, CA); mouse anti-p75 nerve growth factor receptor used at 1:5 with amplification (from Chandler et al., 1984); rabbit anti-trkA used at 1:1250 (gift of Dr. L. Reichert, University of California, San Francisco, CA); and mouse anti-NMDA receptor (anti-NMDAR1) used at 1:1000 (gift of Dr. S. Heinemann, The Salk Institute, La Jolla, CA).

Microscopy. Bright-field sections were imaged and photographed on an Olympus Vanox AH2 microscope (Lake Success, NY) using Kodak Ektachrome 100HC film (Rochester, NY). Selected frames were digitized using a Leaf Lumina digital camera (Leaf Systems, Southborough, MA). Fluorescent sections were imaged using a Bio-Rad MRC600 confocal microscope (Hemel Hempstead, UK) equipped with a krypton/argon laser and coupled to a Zeiss Axiovert $135 \mathrm{M}$ microscope (Thornwood, NY). Images were collected using the K1/K2 block combination; each wavelength was collected using a separate and specific excitation filter and imaged on separate photomultiplier tubes using the COMOS operating system from Bio-Rad. Bright-field and fluorescent digital images were processed using a Power Macintosh 8100 (Apple Computer, Cupertino, CA) running Photoshop 3.01 (Adobe Systems, Mountain View, CA) and Collage 2.01 (Specular International, Amherst, MA). Composited images were output on a Fujix Pictrography 3000 digital photographic printer (Fuji Photo Film, Elmsford, NY).

Stereology. Quantification of ECL2 number was accomplished using unbiased stereology as described in detail previously (Peterson et al., 1994). Briefly, ECL2 in thionin-stained sections was sampled for threedimensional numerical density of neurons using the optical dissector procedure (Sterio, 1984; Peterson and Jones, 1993; Peterson et al., 1994) followed by an estimation of ECL2 volume using the Cavalieri procedure (Michel and Cruz-Orive, 1988; Peterson and Jones, 1993; Peterson et al., 1994). A combination of these two values-numerical density (per unit volume) and reference volume-yields an estimate of total or absolute number of neurons in ECL2. The boundaries used for quantification of ECL2 were those determined by tracer study as described previously (Peterson et al., 1994), which correspond essentially to the medial subdivision of the entorhinal cortex. The optical dissector procedure was accomplished using an Olympus Vanox AH2 microscope equipped with high-numerical-aperture objectives, a digital microcator (Heidenhain, Germany) for encoding $z$-axis travel, and a video camera (Sony) output to a high-resolution video monitor (Sony). An unbiased counting frame (Sterio, 1984) was printed on an acetate sheet and placed over the video screen. The same equipment was used for the Cavalieri procedure except for the use of a low-power objective and a point-counting grid (Michel and Cruz-Orive, 1988) printed on the acetate sheet. Linear calibration was accomplished using a stage micrometer.

Fluorescent labeling was used to examine the phenotype of ECL2 neurons axotomized by the lesion. The primary advantage of fluorescent immunolabels is that multiple labels can be resolved individually, and those individual images then can be recombined in registration to provide unambiguous identification of cell phenotype. The primary antibody NeuN was used to relate the quantitative results of the thionin-stained 


\section{Unlesioned Entorhinal Cortex}

A

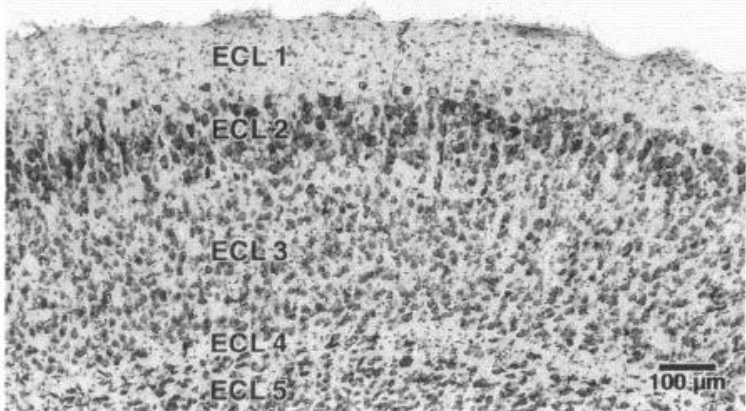

C

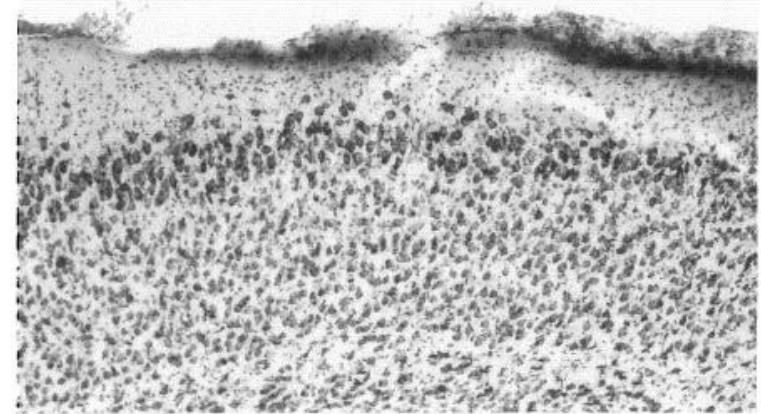

E

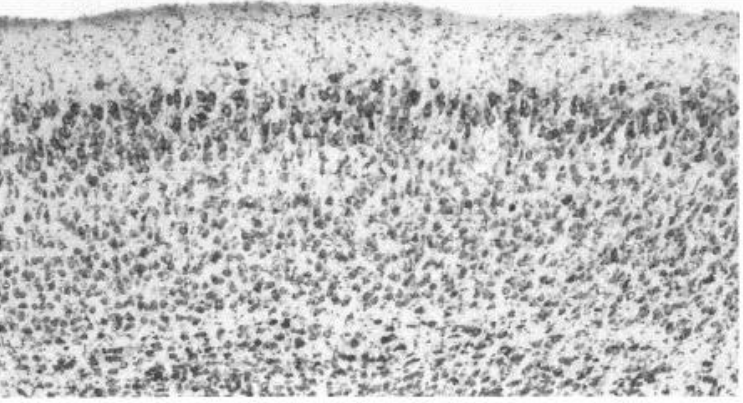

G

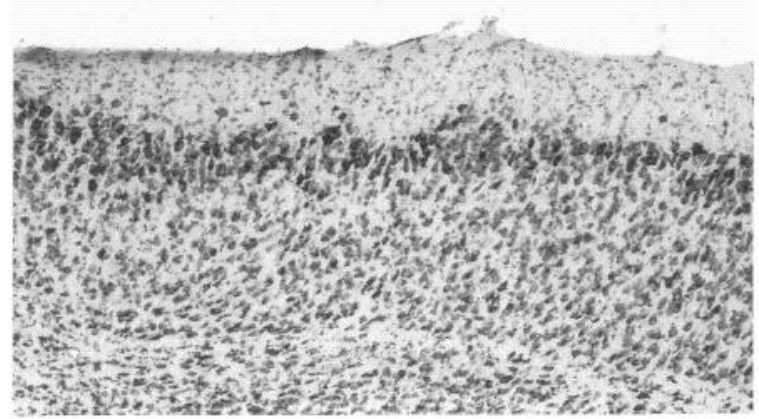

\section{Lesioned Entorhinal Cortex}

B

Control- Gelfoam

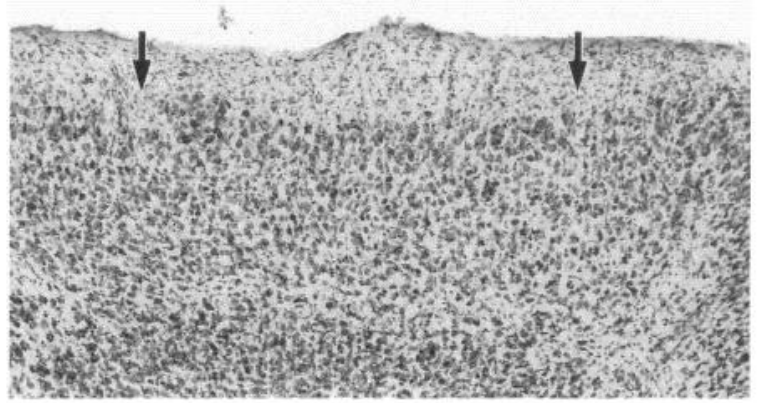

NGF Graft

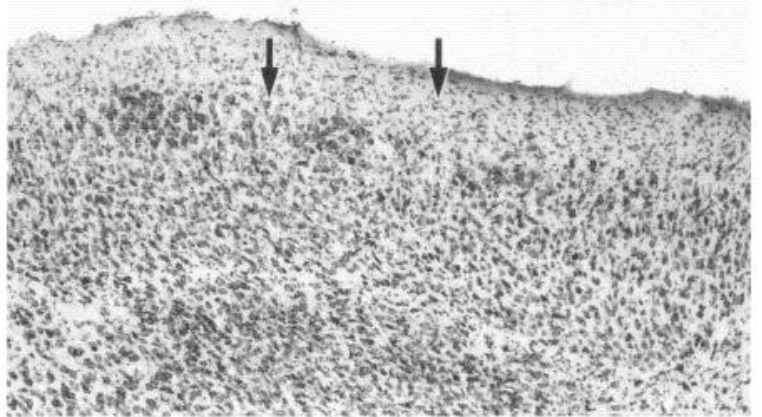

$\mathbf{F}$

FGF-2s Graft

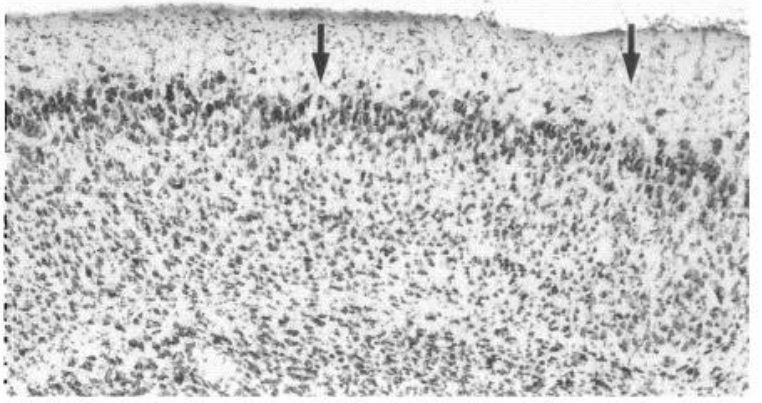

$\mathrm{H}$

FGF-2b Graft

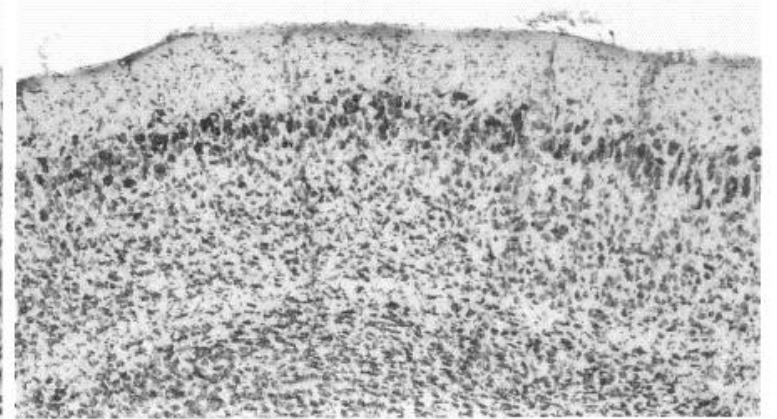

Figure 2. Appearance of the entorhinal cortex in thionin-stained horizontal sections. In unlesioned entorhinal cortex $(A)$, layer II $(E C L 2)$ forms a lamina of large, oval-shaped neurons six to eight cells thick. Above ECL2 is the relatively aneuronal molecular layer designated ECL1. Below ECL2 is another lamina designated ECL3, which consists of smaller, more lightly staining oval neurons. Below this is ECL4, also known as the lamina desicans, which contains few neurons and consists mostly of fiber tracts. At the bottom, there is another layer of neurons (ECL5) below which is the deepest neuronal layer ECL6 (not shown). The appearance of ECL2 remained unchanged in the unlesioned hemisphere at 9 weeks after a perforant pathway lesion (C, $E, G)$. In contrast, the ECL2 on the side receiving a perforant pathway lesion $(B)$ showed considerable thinning of the neuronal population in this lamina (arrows). The same extent of loss was observed in animals receiving NGF grafts $(D$, arrows). Although less marked in qualitative appearance, animals receiving FGF-2s grafts also had thinning and loss of ECL2 neurons $(F$, arrows). However, animals receiving FGF- $2 \mathrm{~b}$ grafts $(H)$ failed to demonstrate neuronal loss in ECL2. Scale bar (shown in $A$ ), $100 \mu \mathrm{m}$ for all panels. 
tissue to the data obtained using fluorescent microscopy. This antibody has been reported to be specific for neuronal populations (Mullen et al., 1992), and immunoperoxidase staining of tissue followed by a thionin counterstain has demonstrated that this is the case for entorhinal neurons (data not shown). We have assumed, therefore, that fluorescently labeled NeuN-positive cells in ECL2 are the same population as the thioninstained ECL2 neurons quantified as described above. This assumption was validated morphologically by cxamining NeuN immunofluorescence counterstained with acridine orange- or 4,6-diamidino-2-phenylindole (DAPI)-fluorescent counterstains to reveal the distribution of $\mathrm{NeuN}$ immunoreactivity relative to all other cell nuclei (data not shown). Because of the shallow penetration of the calbindin antibody, we were unable to quantify the relationship between NeuN-positive cells and calbindin-positive cells in three dimensions. Instead, a single focal plane obtained in the confocal microscope was imaged for both NeuN signal and calbindin signal. The thin optical plane produced by the confocal microscope minimized sampling errors caused by overprojection. The number of cells in the field for each signal was quantified, and the results were cxpressed as a percentage of the NeuN-positive cells in the field that were calbindin-positive. The results were averaged over eight systematically sampled fields in four semiscrial sections, and the mean percentage was multiplied by the number of ECL2 neurons for that animal, as determined by stereological quantification of the thionin-stained sections. The mean of these values for each animal in a condition was taken as the number of calbindin-positive cells for that condition.

The estimates of the glutamatergic neuronal populations were based on the ratio of glutamatergic cells to calbindin-positive cells imaged by double immunofluorescence. The number of cells in a field stained positive for glutamate, calbindin, or coexpressing both glutamate and calbindin was quantificd, and the results were cxpressed as a percentage of the calbindin-positive cells. The results were averaged over eight systematically sampled fields in four semiserial sections, and the mean percentage of glutamatergic, glutamatergic/calbindin-positive, and glutamatergic/calbindin-negative cells was multiplied by the number of calbindin-positive neurons for that animal as determined above. The number of nonphenotyped neurons was calculated for each animal as the number of neurons determined from the thionin-stained sections minus the number of calbindin-positive and glutamatergic/calbindin-negative neurons determined from the above procedures.

Statistical analysis. Quantitative data were compiled and analyzed in StatView 4.01 for the Macintosh (Abacus Concepts, Berkeley, CA), and a multiway ANOVA was performed with an $\alpha$ of 0.05 . After this determination of between-group significance, a Fisher's post hoc test was applied with an $\alpha$ of 0.05 . Error is expressed as SEM.

\section{RESULTS \\ Histological appearance}

A semiserial (1:6) sequence of thionin-stained horizontal sections was examined for each animal to determine the precision of the lesion and position of the graft (Fig. 1). Animals in which the perforant pathway/angular bundle was transected and the lesion cavity contained a graft were included in the study for further analysis. The sample size for each condition was as follows: control-Gelfoam, $n=4$; NGF graft, $n=6$; FGF-2s graft, $n=6$; FGF-2b graft, $n-6$. Histological examination of ECL2 in the control-Gelfoam graft showed regions of neuronal loss similar to those reported previously (Peterson et al., 1994) (Fig. 2B). In contrast, the ECL2 in the hemisphere contralateral to the aspirative lesion showed no evidence of neuronal loss (Peterson et al., 1994) (Fig. 2A,C,E,G). Examination of the ECL2 ipsilateral to the aspirative lesion/graft of animals that received grafts of trophic factor-expressing fibroblasts revealed that ECL2 thinning and neuronal loss were still observed in the NGF graft condition (Fig. $2 D$ ) and, to a lesser degree, in the FGF-2s graft condition (Fig. $2 F$ ), but not in animals that had received grafts of the FGF-2bexpressing fibroblasts (Fig. $2 H$ ). As in our previous study (Peterson et al., 1994), entorhinal layer III showed no obvious cell loss after perforant pathway lesion.

\section{Quantitative stereology}

Analysis of the total number of ECL2 neurons in each condition provided by quantitative stereology demonstrated that, whereas the unlesioned, contralateral ECL2 showed no change in its neuronal population (Peterson et al., 1994) (Table 1A), the lesioned ECL2 neuronal population was affected variably depending on the graft type. When Gelfoam was placed into the lesion cavity as a control graft, the neuronal loss was significant $(p<$ $0.0001)$ and of the same magnitude as reported previously (Peterson et al., 1994) (Tables 1A, 2). Grafts expressing NGF failed to alter the magnitude of neuronal loss; therefore, there was no significant difference compared with the control-Gelfoam grafts $(p$ $=0.5617)$, although the magnitude of loss was significant $(p<$ 0.0001 ) compared with the unlesioned ECL2 (Table 1A). Grafts expressing FGF-2 in the secreted form (FGF-2s) also failed to alter the magnitude of neuronal loss compared with controlGelfoam grafts $(p=0.2326)$, although the loss of ECL2 neurons was significant $(p<0.0001)$ compared with the unlesioned ECL2 (Table $1 A$ ). The effects of NGF grafts and FGF-2s grafts on ECL2 neuronal survival also failed to differ from one another $(p=$ 0.4870 )

Grafting of fibroblasts expressing FGF-2 in its native, membrane-bound form (FGF-2b) caused no loss $(p=0.1422)$ in the number of ECL2 neurons compared with the unlesioned ECL2 (Tables 1A,2). The number of ECL2 neurons in the FGF-2b-grafted animals also was significantly greater $(p=$ 0.0014 ) than in the control-Gelfoam-grafted animals (Table 1A). Furthermore, the number of surviving ECL2 neurons in FGF-2bgrafted animals was significantly greater than that of either the NGF-grafted $(p<0.0001)$ or the FGF-2s-grafted $(p=0.0004)$ animals.

\section{Calbindin immunoreactivity}

Staining with antibodies to calbindin- $\mathrm{D}_{2 \times k}$ illustrated a striking lamina-specific distribution of calbindin-positive neuronal somata and processes (Fig. 3A). Using double labeling with antibodies to NeuN, a neuron-specific antigen, to indicate the laminar distribution of neurons within the entorhinal cortex, calbindin-positive neurons were found almost exclusively in layer II (Fig. 3A-C). Most of layer III was devoid of calbindin-positive cell bodies, although fine, calbindin-positive processes traversed layer III, suggesting axonal projections through this region. Occasionally, isolated calbindin-positive neurons were seen in layer III or layer IV (Fig. $3 A-C$ ). The calbindin cell body-immunonegative zone in layer III extended laterally to the anatomical transition between the entorhinal cortex and adjacent neocortex (Fig. 3A). Thus, calbindin immunoreactivity is specific and characteristic in the rat entorhinal cortex. Calbindin-positive processes were densely packed around their somata and extended into layer I, with a prominent tract of fibers running along layer IV, the lamina desicans (Fig. $3 A-C$ ). These calbindin-positive cells were determined to be neuronal based on their absolute colocalization with antibodies to NeuN (Fig. 3C).

Calculation of the number of calbindin-positive ECL2 neurons obtained by double-labeling confocal microscopy revealed that one-third of ECL2 neurons in unlesioned animals expressed calbindin (Tables $1 B, 2$; Fig. $3 D-F$ ). The population of calbindinpositive neurons was unaffected by the axotomizing lesion because their numbers remained relatively unchanged in lesioned ECL2, independent of the graft condition (Tables $1 B, 2$ ). There was a trend of calbindin-positive cell loss observed in the absence of FGF-2 (Table $1 B$ ), but this was not found to be significant in an 
Table 1. Number of surviving ECL2 neurons at 9 weeks after grafting according to phenotypic identification

\begin{tabular}{|c|c|c|c|c|c|c|}
\hline \multicolumn{2}{|l|}{ A. } & Thionin-stained ECL2 neurons & $( \pm$ SEM $)$ & $p$ & \multicolumn{2}{|c|}{$\begin{array}{l}\text { Relative to unlesioned side } \\
\% \text { Loss }\end{array}$} \\
\hline $\begin{array}{l}\text { Unlesioned } \\
\text { ECL2 }\end{array}$ & $\begin{array}{l}\text { Gelfoam } \\
\text { NGF graft } \\
\text { FGF-2s graft } \\
\text { FGF-2b graft }\end{array}$ & $\begin{array}{r}97690 \\
97982 \\
100201 \\
99712\end{array}$ & $\begin{array}{l}3392 \\
1219 \\
2073 \\
1704\end{array}$ & $\begin{array}{l}\overline{N A} \\
\text { NA } \\
\text { NA }\end{array}$ & & \\
\hline $\begin{array}{l}\text { Lesioned } \\
\text { ECL2 }\end{array}$ & $\begin{array}{l}\text { Gelfoam } \\
\text { NGF graft } \\
\text { FGF-2s graft } \\
\text { FGF-2b graft }\end{array}$ & $\begin{array}{l}71911 \\
74603 \\
77491 \\
93544\end{array}$ & $\begin{array}{l}4679 \\
4668 \\
3498 \\
2186\end{array}$ & $\begin{array}{l}\text { NS } \\
\text { NS } \\
0.0014\end{array}$ & $\begin{array}{l}26 \% \\
24 \% \\
23 \% \\
6 \%\end{array}$ & $\begin{array}{c}<0.0001 \\
<0.0001 \\
<0.0001 \\
\text { NS }\end{array}$ \\
\hline
\end{tabular}

\begin{tabular}{llcrr} 
B. & & Calbindin' ${ }^{\prime}$ ECL2 neurons & $( \pm$ SEM) & $p$ \\
\hline Unlesioned & Gelfoam & 31469 & 978 \\
ECL2 & NGF graft & 30341 & 500 & 877 \\
& FGF-2s graft & 32137 & 1247 & NA \\
& FGF-2b graft & 32113 & 1014 & NA \\
Lesioned & Gelfoam & 26954 & 1759 & 1317 \\
ECL2 & NGF graft & 27425 & 1430 & $N A$ \\
& FGF-2s graft & 29484 & 31179 &
\end{tabular}

Relative to unlesioned side

\begin{tabular}{lll}
$p$ & $\%$ Loss & $p$ \\
\hline NA & & \\
NA & & \\
NA & & \\
& & \\
NA & $14 \%$ & NA \\
NA & $10 \%$ & NA \\
NA & $8 \%$ & NA
\end{tabular}

\begin{tabular}{|c|c|c|c|c|c|c|}
\hline C. & & Glutamate ECL2 neurons & $( \pm$ SEM) & $p$ & Kelative to unlesioned side & $p$ \\
\hline $\begin{array}{l}\text { Unlesioned } \\
\text { ECL2 }\end{array}$ & $\begin{array}{l}\text { Gelfoam } \\
\text { NGF graft } \\
\text { NGF graft } \\
\text { FGF-2s graft } \\
\text { FGF-2b graft }\end{array}$ & $\begin{array}{l}50079 \\
48992 \\
48992 \\
52619 \\
51705\end{array}$ & $\begin{array}{r}935 \\
816 \\
816 \\
1989 \\
1213\end{array}$ & $\begin{array}{l}\overline{\text { NA }} \\
\mathrm{NA} \\
\mathrm{NA} \\
\mathrm{NA}\end{array}$ & & \\
\hline $\begin{array}{l}\text { Lesioned } \\
\text { ECL2 }\end{array}$ & $\begin{array}{l}\text { Gelfoam } \\
\text { NGF graft } \\
\text { FGF-2s graft } \\
\text { FGF-2b graft }\end{array}$ & $\begin{array}{l}29972 \\
32855 \\
34877 \\
49205\end{array}$ & $\begin{array}{r}728 \\
1278 \\
1895 \\
1757\end{array}$ & $\begin{array}{l}- \\
\text { NS } \\
\text { NS } \\
<0.0001\end{array}$ & $\begin{array}{c}40 \% \\
33 \% \\
34 \% \\
5 \%\end{array}$ & $\begin{array}{c}<0.0001 \\
<0.0001 \\
<0.0001 \\
\quad N S\end{array}$ \\
\hline D. & & $\begin{array}{l}\text { Glutamate }{ }^{+} / \text {calbindin }^{+} \\
\text {ECL2 neurons }\end{array}$ & $( \pm$ SEM $)$ & $P$ & $\begin{array}{l}\text { Relative } \\
\% \text { Loss }\end{array}$ & $p$ \\
\hline $\begin{array}{l}\text { Unlesioned } \\
\text { ECL2 }\end{array}$ & $\begin{array}{l}\text { Gelfoam } \\
\text { NGF graft } \\
\text { FGF-2s graft } \\
\text { FGF-2b graft }\end{array}$ & $\begin{array}{l}27693 \\
25935 \\
28732 \\
28671\end{array}$ & $\begin{array}{r}715 \\
591 \\
1114 \\
1050\end{array}$ & $\begin{array}{l}-\overline{N A} \\
\mathrm{NA} \\
\mathrm{NA}\end{array}$ & & \\
\hline $\begin{array}{l}\text { Lesioned } \\
\text { ECL2 }\end{array}$ & $\begin{array}{l}\text { Gelfoam } \\
\text { NGF graft } \\
\text { FGF-2s graft } \\
\text { FGF-2b graft }\end{array}$ & $\begin{array}{l}23376 \\
25565 \\
27677 \\
28510\end{array}$ & $\begin{array}{l}1019 \\
1025 \\
1473 \\
1462\end{array}$ & $\begin{array}{l}-\overline{N A} \\
\mathrm{NA} \\
\mathrm{NA}\end{array}$ & $\begin{array}{l}16 \% \\
1 \% \\
4 \% \\
1 \%\end{array}$ & $\begin{array}{l}\text { NA } \\
\text { NA } \\
\text { NA } \\
\text { NA }\end{array}$ \\
\hline E. & & $\begin{array}{c}\text { Glutamate }{ }^{+} / \text {calbindin } \\
\text { ECL2 neurons }\end{array}$ & $( \pm$ SEM $)$ & $p$ & $\begin{array}{l}\text { Relative } \\
\% \text { Loss }\end{array}$ & $p$ \\
\hline $\begin{array}{l}\text { Unlesioned } \\
\text { ECL2 }\end{array}$ & $\begin{array}{l}\text { Gelfoam } \\
\text { NGT graft } \\
\text { FGF-2s graft } \\
\text { FGF-2b graft }\end{array}$ & $\begin{array}{l}22400 \\
23057 \\
23887 \\
23034\end{array}$ & $\begin{array}{l}1358 \\
1013 \\
1441 \\
1091\end{array}$ & $\begin{array}{l}-\bar{N} \\
\mathrm{NA} \\
\mathrm{NA}\end{array}$ & & \\
\hline $\begin{array}{l}\text { Lesioned } \\
\text { ECL2 }\end{array}$ & $\begin{array}{l}\text { Gelfoam } \\
\text { NGF graft } \\
\text { FGF-2s graft } \\
\text { FGF-2b graft }\end{array}$ & $\begin{array}{r}6596 \\
7290 \\
7201 \\
20695\end{array}$ & $\begin{array}{l}681 \\
520 \\
903 \\
890\end{array}$ & $\begin{array}{l}- \\
\text { NS } \\
\text { NS } \\
<0.0001\end{array}$ & $\begin{array}{l}71 \% \\
68 \% \\
70 \% \\
10 \%\end{array}$ & $\begin{array}{l}<0.0001 \\
<0.00011 \\
<0.0001 \\
\text { NS }\end{array}$ \\
\hline F. & & Nonphenotyped ECL2 neurons & $( \pm$ SEM $)$ & $p$ & $\begin{array}{l}\text { Relative } \\
\% \text { Loss }\end{array}$ & $p$ \\
\hline $\begin{array}{l}\text { Unlesioned } \\
\text { ECL2 }\end{array}$ & $\begin{array}{l}\text { Gelfoam } \\
\text { NGF graft } \\
\text { FGF } 2 \text { s graft } \\
\text { FGF-2b graft }\end{array}$ & $\begin{array}{l}42396 \\
43801 \\
44177 \\
44564\end{array}$ & $\begin{array}{l}2584 \\
1210 \\
2457 \\
1977\end{array}$ & $\begin{array}{l}-\overline{N A} \\
\text { NA } \\
\text { NA }\end{array}$ & & \\
\hline $\begin{array}{l}\text { Lesioncd } \\
\text { ECL2 }\end{array}$ & $\begin{array}{l}\text { Gelfoam } \\
\text { NGFuraft } \\
\text { FGF-2s graft } \\
\text { FGF-2b graft }\end{array}$ & $\begin{array}{l}38361 \\
42356 \\
40806 \\
41670\end{array}$ & $\begin{array}{l}4186 \\
2232 \\
3028 \\
2359\end{array}$ & $\begin{array}{l}\overline{N A} \\
\mathrm{NA} \\
\mathrm{NA}\end{array}$ & $\begin{array}{r}10 \% \\
3 \% \\
8 \% \\
6 \%\end{array}$ & $\begin{array}{l}\text { NA } \\
\text { NA } \\
\text { NA } \\
\text { NA }\end{array}$ \\
\hline
\end{tabular}

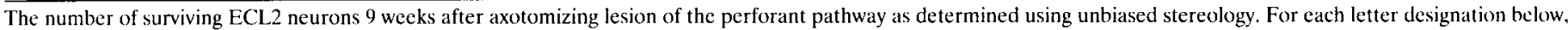

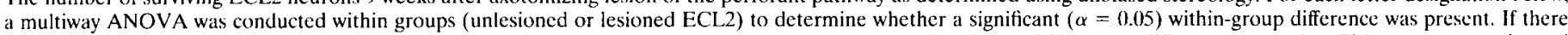

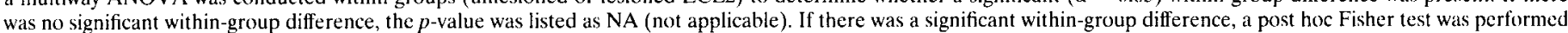

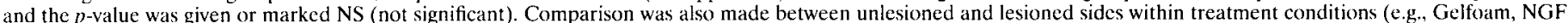

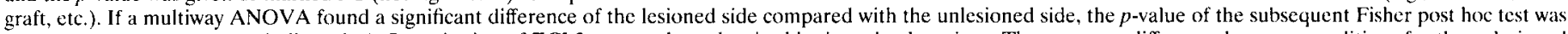

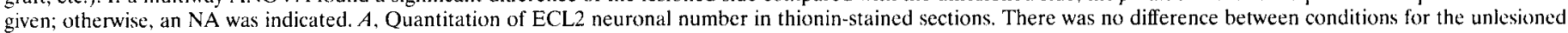

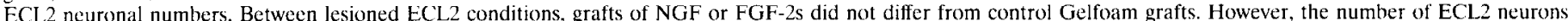

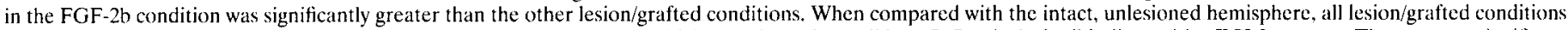

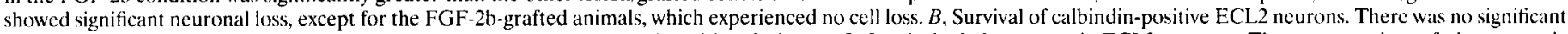

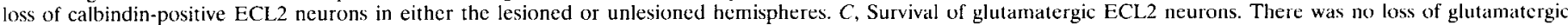

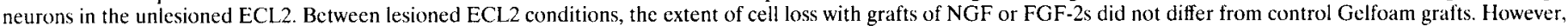

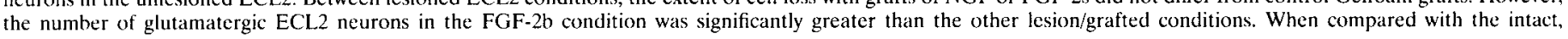


Table 2. Percentage distribution by ECL2 neuronal phenotype relative to total number in the unlesioned control condition

\begin{tabular}{lccccc} 
Phenotype & Unlesioned & Lesioned & Change & $\begin{array}{c}\text { FGF-2b- } \\
\text { grafted }\end{array}$ & Change \\
\hline Thionin & 100 & 74 & $-26^{*}$ & 96 & -4 \\
NeuN & 100 & 74 & $-26^{*}$ & 96 & -4 \\
Calbindirl & 33 & 28 & 5 & 32 & -1 \\
Glutamate $^{*}$ & 51 & 31 & $-20^{*}$ & 50 & -1 \\
Glut $^{+} /$Calh $^{+}$ & 28 & 24 & -4 & 29 & 1 \\
Glut $^{+} /$Calb $^{-}$ & 23 & 7 & $-16^{*}$ & 21 & -2 \\
Nonphenotyped $^{*}$ & 44 & 39 & -5 & 43 & -1
\end{tabular}

The composition of the ECL2 by neuronal phenotype as a percentage of the total number of ECL2 neurons in the unlesioned ECL2. Comparison is made between the lesioned Gelfoam-control graft and FGF-2b-grafted conditions. The NGF-grafted and FGF-2s-grafted conditions are not represented because they did not differ from control-Gelfoam grafts. The percent change for each phenotype in the lesioned/ grafted conditions is indicated, with significant differences from the unlesioned values marked by an asterisk. Percentage values are based on the means of the absolute numbers as presented in Table 1 .

ANOVA test of between-group means. Observation of the ECL2 integrity in NeuN-stained sections for the different conditions (Fig. $3 E, H, K, N, Q$ ) was consistent with the thionin-stained material (Fig. 2) in that all lesion/grafted conditions demonstrated cell loss and disorganization of ECL2, except for animals grafted with FGF-2b (Fig. 3Q). Study of the overlap of calbindin positivity and NeuN positivity in electronically merged images (Fig. $3 F, I, L, O, R$ ) revealed that the neuronal loss was greater in those neurons (NeuN-positive) that did not also express calbindin.

\section{Glutamate immunoreactivity}

To investigate the relationship between calbindin-positive and glutamatergic neurons, sections double labeled with antibodies to calbindin and glutamate were examined by confocal microscopy. In unlesioned entorhinal cortices, glutamate-positive neurons were observed in layers II and III, in which half of the ECL2 neurons were glutamatergic (Tables $1 C, 2$ ). Furthermore, half of the glutamate-positive neurons in layer II were colabeled with calbindin (Fig. $4 A-C$; Tables $1 C, D, 2$ ). Preliminary studies of fluorogold retrogradely transported from dentate gyrus injections revealed that projecting ECL2 neurons are colabeled with antibodies to calbindin (data not shown). Heavily stained processes of glutamatergic cells also were found in layers I-III; the process labeling was so robust that it was difficult to distinguish the glutamatergic somata among the processes (Fig. 4B).

When lesioned/grafted entorhinal cortices were examined, there appeared to be no qualitative differences in glutamate staining among the control Gelfoam-grafted, NGF-grafted, or FGF-2s-grafted animals (Fig. $4 D-L$ ). In all of these conditions, glutamate staining was reduced (Fig. $4 E, H, K$ ), especially in neuronal processes, causing glutamatergic neuronal somata to be more distinct. When quantified, the population of glutamatergic neurons declined from one-half to one-third of the total neuronal population (Table 2). Assessing the subpopulations of glutamatergic neurons after lesioning revealed that the number of glutamatergic/calbindin-negative neurons was severely reduced, to $30 \%$ of that of the contralateral control population (Fig. $4 F, I, L$; Table $1 E$ ). In real terms, the number of glutamatergic/calbindinnegative neurons was reduced from 23 to $7 \%$ of the total neuronal population (Table 2). However, quantitation of the glutamatergic/ calbindin-positive neuronal population revealed that this phenotype was unaffected by the lesion (Tables $1 D, 2$ ). Furthermore, the loss of so many glutamatergic/calbindin-negative neurons meant that, of the surviving glutamatergic neurons, $>75 \%$ coexpressed calbindin (Fig. $4 F, I, L$; Tables $1 C, D, 2$ ).

In contrast, animals with FGF-2b grafts showed levels of glutamate expression equivalent to the unlesioned side (Fig. $4 N$ ). Of importance, the number of glutamatergic/calbindin-negative neurons also was unchanged from control levels (Fig. 4O; Tables $1 E$, 2 ). Thus, in the control Gelfoam-grafted, NGF-grafted, and FGF2 s-grafted conditions, the glutamatergic/calbindin-negative neuronal population was vulnerable to cell death caused by the perforant pathway lesion. In contrast, those animals that received FGF-2b grafts demonstrated no loss within this vulnerable population. These data are based on phenotypic recognition of characteristic cellular antigens; although reduced expression of glutamate immunoreactivity was observed, this could represent downregulation of this amino acid rather than the death of the neuron. However, the magnitude of loss documented with the glutamatergic/calbindin-negative phenotype (Tables $1 E, 2$ ) is consistent with that observed after quantitation of the thionin-stained material (Tables $1 A, 2$ ), which suggests that the observed effect is attributable to neuronal cell death. Regardless of whether the observations made represent cell death or expression downregulation, glutamatergic/calbindin-negative neurons lose their functional phenotype after perforant pathway transection unless they are supported by exogenous FGF-2.

\section{Nonphenotyped neurons}

Double-immunofluorescence staining with antibodies to glutamate and calbindin did not identify all neuronal phenotypes present within the ECL2. It is important to note that calbindinnegative/glutamate-negative neurons exist in the entorhinal cortex (Fig. $4 C$, arrowheads). Calculating the number of nonphenotyped neurons in the ECL2 revealed that this population accounts for $-40 \%$ of the neuronal population of the ECL2 (Tables $1 A, F, 2$ ). Of importance, this population of unidentified neuronal phenotype was nonresponsive to lesion of the perforant pathway and to the presence of trophic factor-expressing grafts (Tables $1 F, 2$ ).

$\overline{\text { unlesioned }} \overline{\text { hemisphere, all lesion/grafted conditions showed significant glutamatergic neuron loss except for the FGF-2b-grafted animals, which }}$ experienced no cell loss. Because the glutamatergic population consisted of two subtypes, those that coexpressed calbindin and those that did not, these subpopulations are represented separately below. $D$, Survival of glutamatergic/calbindin-positive ECL2 neurons. There was no significant loss of this subpopulation of glutamatergic/calbindin-positive ECL2 neurons in either the lesioned or the unlesioned hemispheres. $E$, Survival of glutamatergic/ calbindin-negative ECL2 neurons. There was no ECL2 ncuronal loss in the unlesioned hemispheres. Between lesioned ECL2 conditions, the extent of cell loss with grafts of NGF or FGF-2s did not differ from control Gelfoam grafts. However, the number of glutamatergic/calbindin-negative ECL2 neurons in the FGF-2b condition was significantly greater than the other lesion/grafted conditions. When compared with the intact, unlesioned hemisphere, all lesion/grafted conditions showed significant glutamatergic/calbindin-negative neuron loss, except for the FGF-2b-grafted animals, which experienced no cell loss. This is the population that is most vulnerable to perforant pathway lesion and that demonstrates a trophic response to FGF-2. $F$, Survival of other, nonphenotyped ECL2 neurons. There was no significant loss of this subpopulation of ECL2 neurons of unidentified phenotype in either the lesioned or the unlesioned hemispheres. 

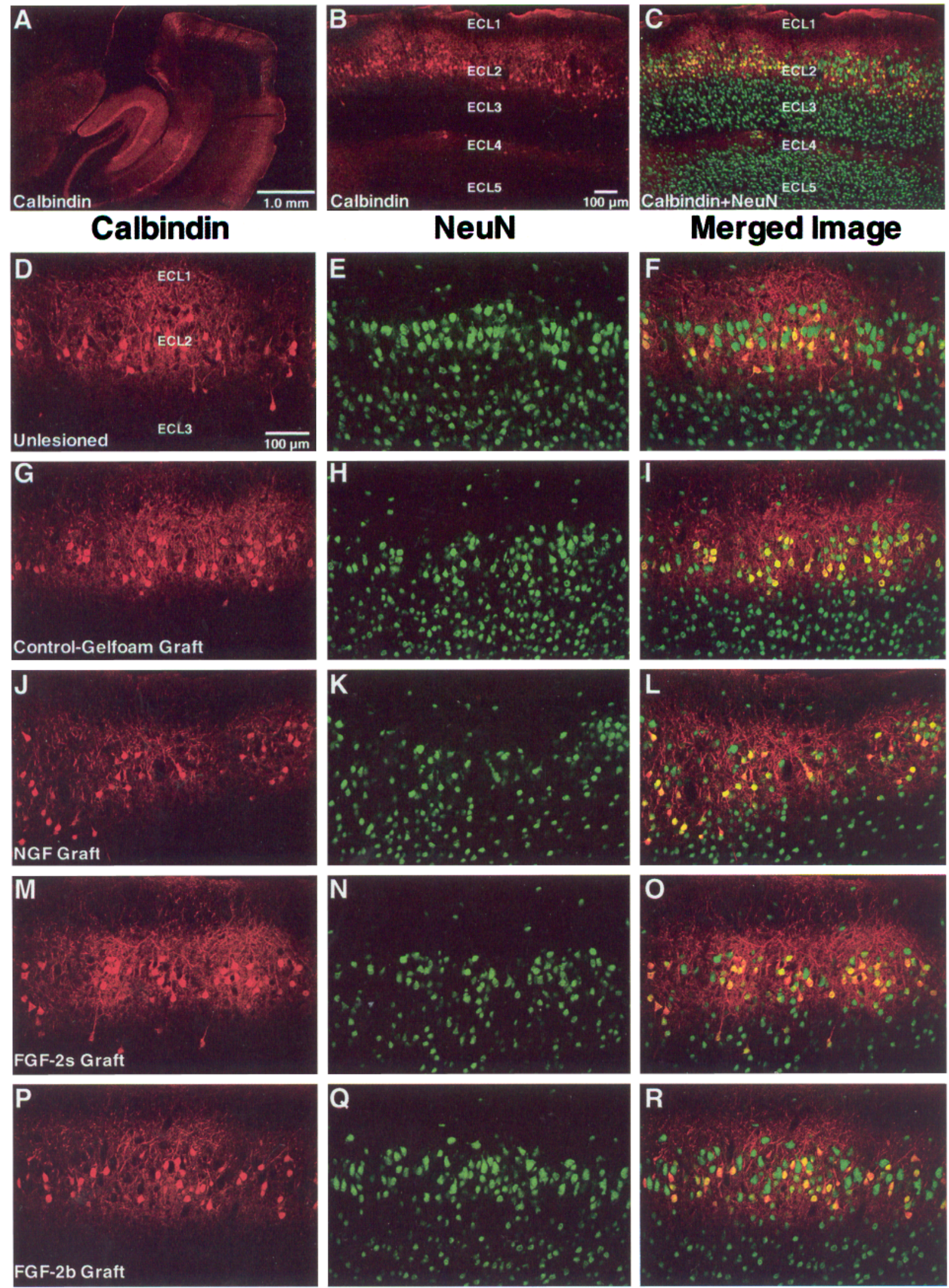


\section{Receptor staining}

To elucidate mechanisms of neuronal cell death and to provide information on which to base strategies for intervention, ECL2 neurons were characterized for their expression of relevant receptors. Double-immunofluorescence staining of sections with antibodies to calbindin and NMDAR1 revealed that ECL2 neurons express NMDAR1 at high concentration in the cell bodies, to a lesser extent on neuronal processes, and at low density in the nuclear region (Fig. 5A). Both calbindin-positive and calbindinnegative ECL2 ncurons express NMDAR1 (Fig. 5B,C). Nlthough quantitation of NMDAR1 staining was not attempted, it appeared that most, if not all, ECL2 neurons expressed NMDAR1.

Adjacent sections also were stained for antibodies against the p75 low-affinity NGF receptor, the high-affinity NGF receptor trkA, and the FGF-2 flg receptor FGFR1. Although both p75 low-affinity NGF receptor-positive neurons and trkA high-affinity NGF receptor-posilive neurons could be detected in areas where they are known to occur, no positive cells were observed in ECL2 (data not shown). However, numerous ECL2 cells, both neuronal and non-neuronal, stained positive for the FGFR1 antibody (Fig. $5 D$ ). Astrocytes are known to express FGFR1 (Balaci et al., 1994). Staining for FGFRI was localized in cell bodies and cell processes but was absent in the nucleolar region (Fig. 5D). Colocalization with antibodies against calbindin demonstrated that both calbindin-positive and calbindin-negative ECL2 neurons expressed FGFR1 (Fig. $5 E, F$ ). These data provided the rationale for the choice of grafting trophic factor-expressing cells. This same pattern of FGFR1 immunoreactivity was observed in the lesioned ECL2 of all graft conditions (data not shown). Although quantitation of FGFR1 staining was not attempted, it appeared that most, if not all, ECL2 neurons expressed FGFR1.

\section{DISCUSSION}

We present three major findings in this report. First, we describe the specific patterns of calbindin-positive cells in the rat entorhinal cortex, demonstrate the extensive colocalization of calbindin with glutamate in ECL2, and provide quantitative estimates for these populations of ECL2 neurons. Second, we demonstrate that the previously described ECL2 neuronal death caused by perforant pathway lesion (Peterson et al., 1994) can be attributed to a specific vulnerable subpopulation of ECL2 neurons, namely, the glutamatergic/calbindin-negative neurons. Third, we show that this vulnerable population of neurons can be rescued by the appropriate trophic factor support from FGF-2b-expressing fibroblast grafts. In conclusion, we offer a hypothesis of the sequence of neuronal vulnerability and the mechanism of trophic factor rescue suggested by these data.

\section{Phenotypic identification of ECL2 neurons}

Calbindin- $\mathrm{D}_{28 \mathrm{k}}$ is one of a number of calcium-binding proteins including parvalbumin and calretinin expressed in the central nervous system. Calcium-binding proteins are thought to enable these neurons to survive overloading of calcium homeostasis caused by excitotoxic insult (Mattson et al., 1991; Miller, 1991). In both an experimental model of Parkinson's disease (Iacopino et al., 1992) and in postmortem Parkinson brains (Yamada et al., 1990), surviving nigral dopaminergic neurons coexpressed calbindin. However, calbindin levels were reduced in Alzheimer's disease (Ichimiya et al., 1988; Iacopino and Christakos, 1990; Hof and Morrison, 1991; Ferrer et al., 1993), and in Parkinson's and Huntington's diseases (Iacopino and Christakos, 1990), which suggests that calbindin-expressing neurons fail to survive the neurodegenerative progression of these diseases.

Although the distribution of calbindin immunoreactivity has been described for human entorhinal cortex (Beall and Lewis, 1992; Tunon et al., 1992), calbindin-immunoreactive cytoarchitecture in the rat entorhinal cortex has not been described in detail (Celio, 1990). We report that calbindin-positive neurons are found almost exclusively in layer II, in which they are colocalized with the glutamatergic projection neurons known to make the major contribution to the perforant pathway (Witter, 1993).

The stability of the calbindin-positive neuronal population suggests that calcium-binding protein expression facilitates survival of these cells independent of trophic support. Although most glutamatergic/calbindin-negative neurons were vulnerable to the lesion, a small population survived even in the absence of FGF-2. These particular glutamatergic neurons may not contribute to the perforant pathway, but project elsewhere or have multiple projections (Witter, 1993), or they may express one of the other calcium-binding proteins (Demeulemeester et al., 1991; Gulyas et al., 1991; Morino-Wannier et al., 1992; Rogers, 1992; Toth and Freund, 1992). Alternatively, these surviving ECL2 glutamatergic neurons may die eventually if examined during a longer postlesion time interval (Peterson et al., 1994).

\section{FGF-2b rescue of glutamatergic/calbindin-negative ECL2 neurons}

FGF-2 cnhances neuron survival and promotes neurite outgrowth when added to cultures from a variety of brain regions, including entorhinal cortex (Walicke, 1988) and hippocampus (Walicke et al., 1986; Walicke, 1988; Ray et al., 1993). Furthermore, addition of FGF-2 protects cultured neurons from a variety of cytotoxic insults, including excitotoxins (Freese et al., 1992; Louis et al., 1993; Mattson et al., 1993b; Skaper et al., 1993), ischemia (Cheng and Mattson, 1991, 1992; Cheng et al., 1993; Louis et al., 1993),

$\leftarrow$

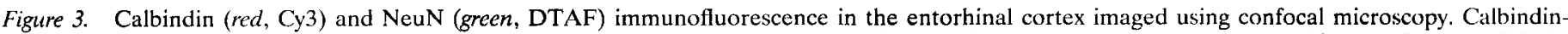

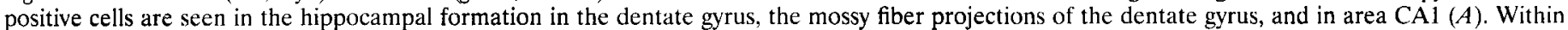

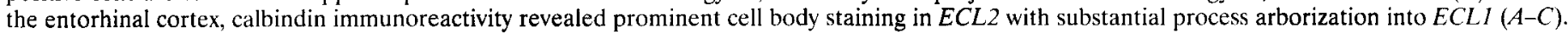

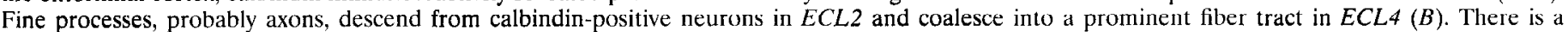

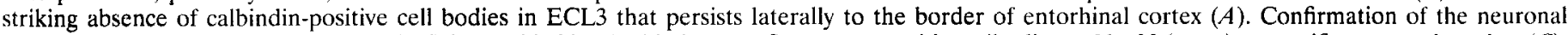

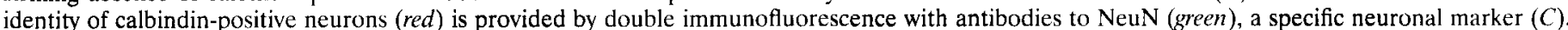

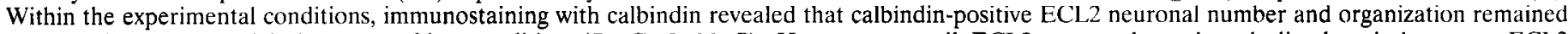

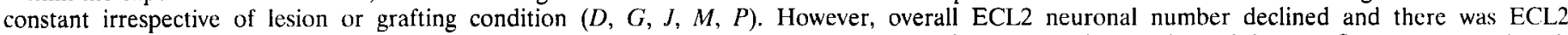

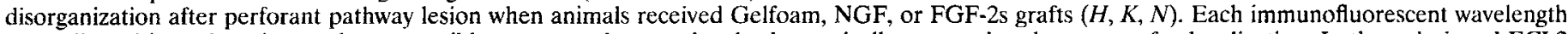

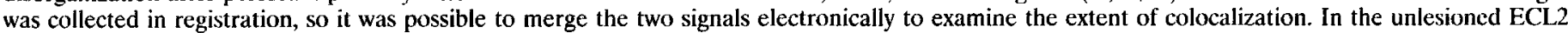

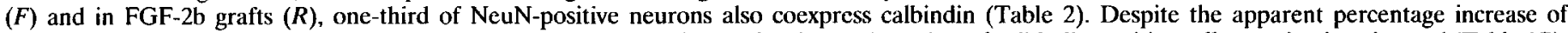

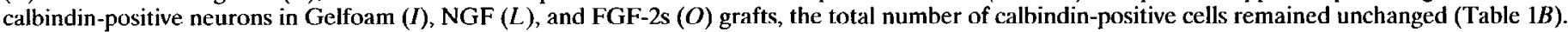

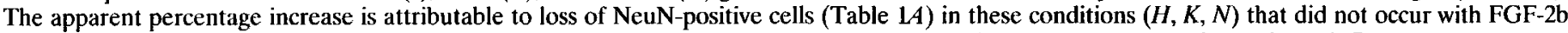
grafts $(Q)$. Scale bar: $1.0 \mathrm{~mm}$ in $A$. Scale bar (shown in $B$ ): $100 \mu \mathrm{m}$ for $B$ and $C$. Scale bar (shown in $D$ ): $100 \mu \mathrm{m}$ for $D$ through $R$. 

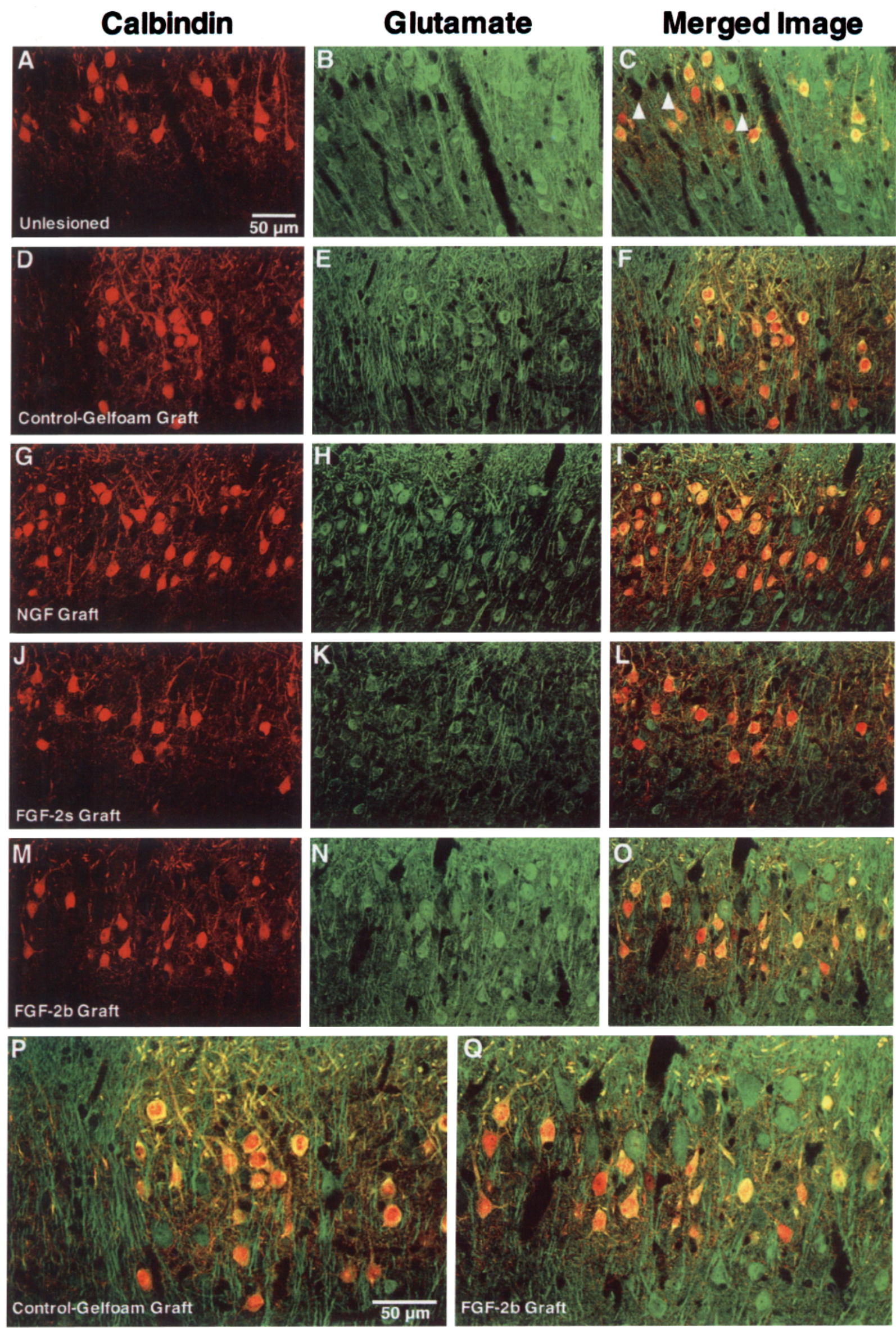


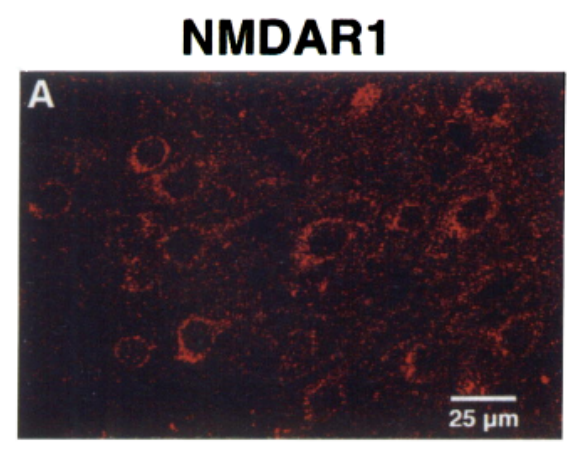

FGFR1

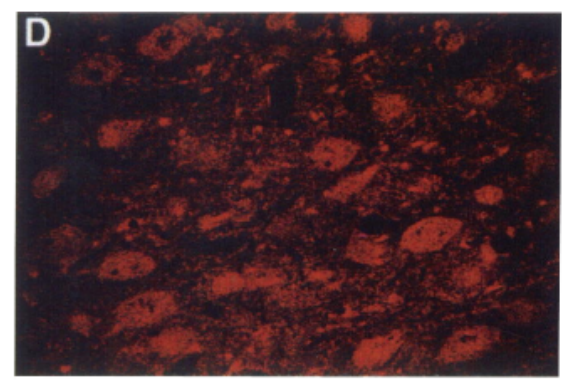

Calbindin

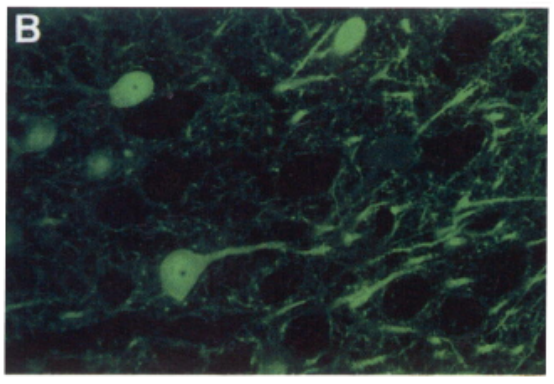

Calbindin

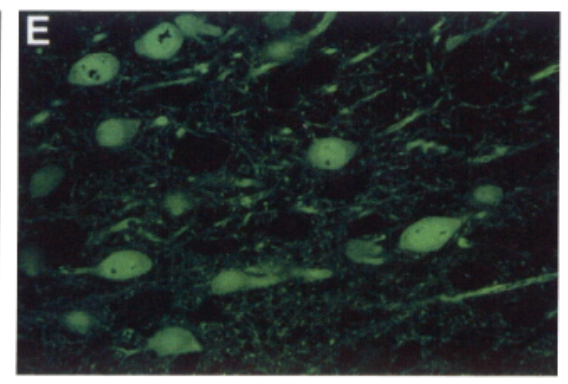

Merged Image

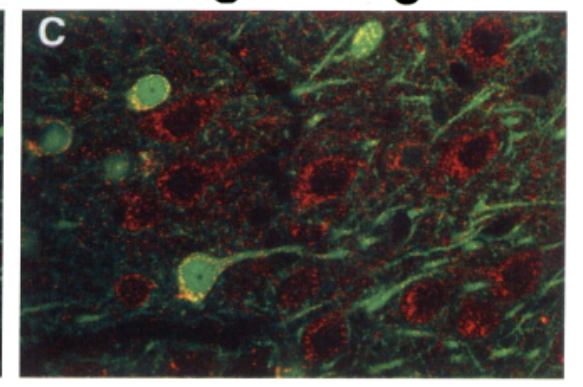

Merged Image

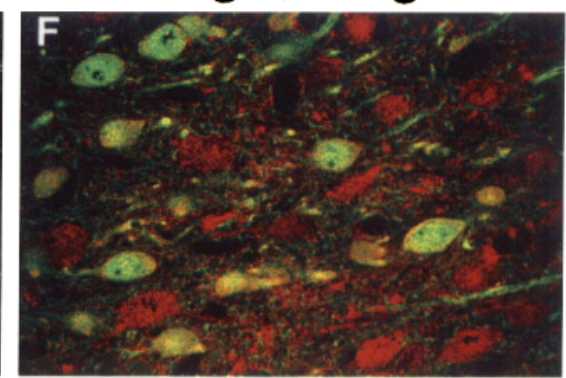

Figure 5. Localization of receptors for NMDA and FGF-2 in ECL2 neurons imaged using confocal microscopy. A, NMDAR1 (red, Cy3) is localized in punctate staining at high density in ECL2 neuronal somata, with the exception of the nucleus, in which staining is at a lower density. Some staining of proximal fibers is also present. $B$, Calbindin-positive ECL2 neurons (green, DTAF) imaged in the same field of view as $A$. $C$, Electronic merging of the registered images in $A$ and $B$ shows that most ECL2 neurons, calbindin-positive and -negative, express the NMDAR1. $D$, The $f g$ receptor for FGF-2, FGFR1 (red, Cy3) is found on both neuronal and non-neuronal ECL2 cells localized in punctate staining at high density in cell bodies and processes. Only the nucleolar region is devoid of FGFR1 staining. $E$, Calbindin-positive ECL2 neurons (green, DTAF) imaged in the same field of view as $D . F$, Electronic merging of the registered images in $D$ and $E$ shows that most ECL2 neurons, calbindin-positive and -negative, express FGFR1. Scale bar, $25 \mu \mathrm{m}$ for all panels.

and oxidative stress (Enokido et al., 1992). A neuroprotective role for FGF-2 also has been reported in vivo in experimental models administering FGF-2 in conjunction with lesions of the medial septum (Anderson et al., 1988; Otto et al., 1989), striatum (Otto and Unsicker, 1990; Nozaki et al., 1993), thalamus (Yamada et al., 1991), entorhinal cortex (Cummings et al., 1992), and spinal cord (Blottner and Baumgarten, 1992a,b).

Unlike other neurotrophins, FGF-2 is not secreted from cells; rather, it is expressed in a membrane-associated form in which its sequestration by the extracellular matrix protects it from nonspecific proteolytic or thermal degradation (Klagsbrun, 1989). The response of neurons is mediated by the high-affinity FGFR1 (Asai et al., 1993), which internalizes FGF-2 where it is cleaved into two metabolic fragments and transported to the neuronal nucleus (Walicke and Baird, 1991). We report here that ECL2 neurons express FGFR1. Consistent with our previous studies (Ray et al., 1995; Takayama et al., 1995), the results presented here suggest that FGF-2b elicits a greater neurotrophic response than does FGF-2s.

Nevertheless, the absence of a neuroprotective effect with FGF-2s grafts was unexpected in view of previous reports of neuroprotection in vivo after FGF infusions. This may be attributable to FGF-2 concentration differences between chronic infusions and the production of the FGF-2s fibroblasts. In fact, extracellular matrix-sequestered FGF-2b should achieve a higher local concentration than the FGF-2s. Furthermore, secreted FGF-2 would have been vulnerable to proteolytic degradation. Finally, Western blot analysis of FGF-2 released in the media of FGF-2s cultures revealed that a majority of FGF-2 protein was the $35 \mathrm{kDa}$ form reported to be inactive, whereas the active $18 \mathrm{kDa}$ form was

Figure 4. Calbindin (red, Cy3) and glutamate (green, DTAF) immunofluorescence in the entorhinal cortex imaged using confocal microscopy. Although calbindin-positive cell staining remained unaffected by lesion or grafting $(A, D, G, J, M)$, as observed previously (Fig. 3), entorhinal glutamate staining was changed by perforant pathway lesion. Glutamate immunofluorescence of the intact entorhinal cortex $(B)$ revealed strong labeling of neuronal somata and fibers; fiber staining was so robust that individual somata are difficult to discern. However, lesion of the perforant pathway followed by Gelfoam $(E)$, NGF $(H)$, or FGF-2s $(K)$ grafts showed a marked attenuation of glutamate staining, which also helped to make the presence of glutamatergic neuronal somata more distinct. When colocalization of glutamate with calbindin was examined, the unlesioned ECL2 (C) revealed that, although most calbindin-positive cells expressed glutamate, some did not. Of the more numerous glutamatergic cells in ECL2, 50\% expressed calbindin (Table 2). Fluorescent-negative regions suggest that not all ECL2 neurons express glutamate or calbindin ( $C$, arrowheads). When coexpression in lesion/grafting conditions was examined, it was observed that most of the surviving ECL2 glutamatergic neurons in animals receiving Gelfoam $(F$, see also $P$ ), NGF $(I)$, or FGF-2s $(L)$ grafts also expressed calbindin. Only a minority of glutamatergic neurons not expressing calbindin were observed in these conditions (Table 2). These results illustrate that the population of glutamatergic/calbindin-negative ECL2 neurons is vulnerable to perforant pathway lesion. Animals that received FGF-2b grafts demonstrate equivalent glutamate staining $(N)$ and the same ratio of calbindin coexpression of glutamatergic ECL2 neurons $(O$, see also $Q$ ) as the unlesioned animals $(C)$. To illustrate this distinction further in the FGF-2b-grafted animals, a higher-power view $(Q)$ is contrasted with the control-Gelfoam condition $(P)$. These results illustrate that FGF-2b prevents the death of the vulnerable glutamatergic/calbindin-negative ECL2 neurons. Scale bar (shown in $A$ ): $50 \mu \mathrm{m}$ for $A$ through $O$. Scale bar (shown in $P$ ): $50 \mu \mathrm{m}$ for $P$ and $Q$. 
present at low levels (Ray et al., 1995), suggesting that the FGF-2s grafts were of limited utility in presenting active FGF-2 to the ECL2 neurons.

\section{Hypothesis of cell death/rescue}

The postlesion survival of glutamatergic/calbindin-positive neurons in the absence of FGF-2 may reflect a sequence of excitotoxicity and oxidative stress followed by calbindin-mediated intracellular calcium buffering. Axotomy of glutamatergic ECL2 neurons may lead to a transitory increase in local extracellular glutamate concentrations, as was reported after ischemia (Graham et al., 1990) or concussive injury (Katayama et al., 1990). Glutamate is the major effector of oxidative stress in the brain, acting primarily via ionotropic receptors opening ion channels. The resultant calcium influx produces oxygen radicals, which has serious cytotoxic consequences (Coyle and Puttfarcken, 1993). We have demonstrated that most ECL2 neurons express NMDAR1 and, therefore, would be susceptible to extracellular glutamate concentrations. Of interest, injection of excitotoxins into the entorhinal cortex can cause loss of layer II (Levisohn and Isacson, 1991; Yee et al., 1993) or layer III neurons (Du and Schwarcz, 1992; Eid et al., 1994).

The neuroprotective function of FGF-2 has been investigated using experimental manipulations modeling excitotoxicity (Freese et al., 1992; Liu et al., 1993; Nozaki et al., 1993; Skaper et al., 1993), ischemia (Nakata et al., 1993; Nozaki et al., 1993; Regli et al., 1994), and oxidative stress (Enokido et al., 1992). One common component of these investigations has been the modulation of intracellular calcium levels. Studies conducted by Mattson and coworkers modeling excitotoxicity (Mattson et al., 1993b), ischcmia (Cheng and Mattson, 1991, 1992; Cheng ct al., 1993; Mattson et al., 1993c), and oxidative stress (Zhang et al., 1993), in addition to reports by others (Ferhat et al., 1993; Louis et al., 1993), have confirmed that changes in intracellular calcium are specifically modulated by FGF-2. Modulation of intracellular calcium also has been described for a number of other neurotrophic factors, including NGF (Mattson and Cheng, 1993; Mattson et al., 1993a).

However, NGF failed to protect the vulnerable glutamatergic/ calbindin-negative neurons. Furthermore, staining with antibodies to both the high-affinity trkA and low-affinity p75 NGF receptors reveals that layer II neurons do not possess receptors for NGF (data not shown). The difference in efficacy also may be explained by a mechanism unique to FGF-2 by which intracellular calcium may be stabilized. For example, Mattson et al. (1993d) reported that the expression of the glutamate-binding subunit of the NMDA receptor (NMDARP-71) is sclectivcly suppressed by FGF-2. The disabling of this receptor may prevent neuronal response to glutamate, thereby obviating challenge to intracellular calcium homeostasis. Via this mechanism, FGF-2, but not NGF or EGF (Mattson et al., 1993d), may regulate the calcium pathways of the neuron.

Based on these data, we propose a two-part hypothesis describing the cascuade of events leading to the axolomy-induced death of the vulnerable glutamatergic/calbindin-negative neurons and their rescue by FGF-2. We propose that local extracellular glutamate levels are increased in layer II because of cellular damage to glutamatergic ECL2 neurons after the axotomizing lesion. This increased extracellular glutamate may activate the NMDAR1 present on these ECL2 neurons, causing a calcium influx. Those glutamatergic cells that coexpress calbindin would be able to buffer this calcium, whereas the vulnerable calbindin-negative population would undergo calcium-mediated oxidative stress culminating in their death. As a second part to the hypothesis, we propose that $\mathrm{FGF}-2$ rescues the vulnerable glutamatergic/ calbindin-negative by obstructing the initiation of calciummediated oxidative stress. The mechanism for this may be that described above by which the NMDAR 1 capacity is compromised in the presence of FGF-2 (Mattson et al., 1993d). Future experiments will be directed toward testing these hypotheses.

The data presented here implicate the loss of calcium homeostasis in the death of the axotomized glutamatergic/calbindinnegative neurons. The rescue of this population of neurons by the availability of FGF-2 suggests that therapeutic strategies can be developed to prevent neuronal death caused by calcium-mediated cytotoxic stress in cases of excitotoxicity, ischemia, physical trauma and, possibly, in neurodegenerative diseases. The demonstration of neuroprotection in the entorhinal cortex, a region of specific neurodegeneration in Alzheimer's disease, suggests that further studies should be designed to test hypotheses of mechanisms by which neurodegeneration may be prevented.

\section{REFERENCES}

Abraham WC, Mason SE, Demmer J, Williams JM, Richardson CL, Tate WP, Lawlor PA, Dragunow M (1993) Correlations between immediate early gene induction and the persistence of long-term potentiation. Neuroscience 56:717-727.

Anderson KJ, Dam D, Lee S, Cotman CW (1988) Basic fibroblast growth factor prevents death of lesioned cholinergic neurons in vivo. Nature 332:360-361

Armstrong DM, Ikonomovic MD, Sheffield R, Wenthold RJ (1994) AMPA-selective glutamate receptor subtype immunoreactivity in the entorhinal cortex of non-demented elderly and patients with Alzheimer's disease. Brain Res 639:207-216.

Arnold SE, Hyman BT, Vanhoesen GW, Damasio AR (1991) Some cytoarchitectural abnormalities of the entorhinal cortex in schizophrenia. Arch Gen Psychiatry 48:625-632.

Asai T, Wanaka A, Kato H, Masana Y, Seo M, Tohyama M (1993) Differential expression of two members of FGF receptor gene family, FGFR-1 and FGFR-2 mRNA, in the adult rat central nervous system. Mol Brain Res 17:174-178.

Balaci L, Presta M, Ennas MG, Dell'Era P, Sogos V, Lauro G, Gremo F (1994) Differential expression of fibroblast growth factor receptors by human neurones, astrocytes and microglia. NeuroReport 6:197-200.

Beall MJ, Lewis DA (1992) Heterogeneity of layer-II neurons in human entorhinal cortex. J Comp Neurol 321:241-266.

Bliss TVP, Lømo T (1973) Long-lasting potentiation of synaptic transmission in the dentate area of the anaesthetized rabbit following stim ulation of the perforant path. J Physiol (Lond) 232:331-356.

Blottner D, Baumgarten HG (1992a) Basic fibroblast growth factor prevents neuronal death and atrophy of retrogradely labeled preganglionic neurons in vivo. Exp Neurol 118:35-46.

Blottner D, Baumgarten HG (1992b) Insulin-like growth factor-I counteracts bFGF-induced survival of nitric oxide synthase (NOS)-positive spinal cord neurons after target-lesion in vivo. $J$ Neurosci Res 32:471-480.

Braak H, Braak E (1992) The human entorhinal cortex: normal morphology and lamina-specific pathology in various diseases. Neurosci Res 15:6-31

Celio MR (1990) Calbindin D-28k and parvalbumin in the rat nervous system. Neuroscience 35:375-475.

Chandler CE, Parson LM, Hosang M, Shooter EM (1984) A monoclonal antibody modulates the interaction of nerve growth factor with $\mathrm{PC} 12$ cells. J Biol Chem 259:6882-6889.

Cheng B, Mattson MP (1991) NGF and bFGF protect rat hippocampal and human cortical neurons against hypoglycemic damage by stabilizing calcium homeostasis. Neuron 7:1031-1041.

Cheng B, Mattson MP (1992) Glucose deprivation elicits neurofibrillary tangle-like antigenic changes in hippocampal neurons: prevention by NGF and bFGF. Exp Neurol 117:114-123.

Cheng B, McMahon DG, Mattson MP (1993) Modulation of calcium current, intracellular calcium levels and cell survival by glucose depri- 
vation and growth factors in hippocampal neurons. Brain Res 607:275-285.

Coyle JT, Puttfarcken P (1993) Oxidative stress, glutamate, and neurodegenerative disorders. Science 262:689 695.

Cummings BJ, Yee GJ, Cotman CW (1992) bFGF promotes the survival of entorhinal layer-II neurons after perforant path axotomy. Brain Res 591:271-276.

Demeulemeester H, Arckens L, Vandesande F, Orban GA, Heizmann CW, Pochet R (1991) Calcium binding proteins and neuropeptides as molecular markers of GABAergic interneurons in the cat visual cortex. Exp Brain Res 84:538-544.

Du F, Schwarcz R (1992) Aminonxyacetic acid causes selective neuronal loss in layer-III of the rat medial entorhinal cortex. Neurosci Lett 147:185-188.

Eid T, Du F, Schwarcz R (1994) Differential ncuronal vulncrability to aminooxyacetic acid and quinolinic acid in the rat entorhinal cortex. Soc Neurosci Abstr 24:270.

Enokido Y, Akaneya Y, Niinobe M, Mikoshiba K, Hatanaka H (1992) Basic fibroblast growth factor rescues CNS neurons from cell death caused by high oxygen atmosphere in culture. Brain Res 599:261-271.

Falkai P, Bogerts B, Rozumek M (1988) Limbic pathology in schizophrenia: the entorhinal region-a morphometric study. Biol Psychol 24:515-521.

Ferhat L, Khrestchatisky M, Roisin MP, Barbin G (1993) Basic fibroblast growth factor-induced increase in zif/268 and c-fos mRNA levels is $\mathrm{Ca}^{2+}$ dependent in primary cultures of hippocampal neurons. J Neurochem 61:1105-1112.

Ferrer I, Tunon T, Soriano E, del Rio A, Iraizoz I, Fonseca M, Guionnet N (1993) Calbindin D-28k immunoreactivity in the temporal neocortex in patients with Alzheimer's disease. Clin Neuropathol 12:53-58.

Fisher LJ, Jinnah HA, Kale LC, Higgins GA, Gage FH (1991) Survival and function of intrastriatally grafted primary fibroblasts genetically modified to produce L-dopa. Neuron 6:371-380.

Freese A, Finklestein SP, DiFiglia M (1992) Basic fibroblast growth factor protects striatal neurons in vitro from NMDA receptor-mediated excitotoxicity. Brain Res 575:351-355.

Graham SH, Shiraishi K, Panter SS, Simon RP, Faden AI (1990) Changes in extracellular amino acid neurotransmitters produced by focal cerebral ischemia. Neurosci Lett 110:124-130.

Gulyas AI, Toth K, Danos P, Freund TF (1991) Subpopulations of GABAergic neurons containing parvalbumin, calbindin D28k, and cholecystokinin in the rat hippocampus. J Comp Neurol 312:371-378.

Heinemann U, Zhang CL, Eder C (1993) Entorhinal cortexhippocampal interactions in normal and epileptic temporal lobe. Hippocampus 3:89 97.

Hof PR, Morrison JH (1991) Neocortical neuronal subpopulations labeled by a monoclonal antibody to calbindin exhibit differential vulnerability in Alzheimer's disease. Exp Neurol 111:293-301.

Hyman BT, Damasio AR, Van Hoesen GW, Barnes CL (1984) Alzheimer's disease: cell specific pathology isolates the hippocampal formation. Science 225:1168-1170.

Hyman BT, Van Hoesen GW, Kromer LJ, Damasio AR (1986) Perforant pathway changes and the memory impairment of Alzheimer's disease. Ann Neurol 20:472-481.

Iacopino AM, Christakos S (1990) Specific reduction of calcium-binding protcin (28-kilodalton calbindin-D) gene cxpression in aging and ncurodegenerative diseases. Proc Natl Acad Sci USA 87:4078-4082.

Iacopino AM, Christakos S, German D, Sonsalla PK, Altar CA (1992) Calbindin-D28K-containing neurons in animal models of neurodegeneration: possible protection from excitotoxicity. Mol Brain Res 13:251-261.

Ichimiya Y, Emson PC, Mountjoy CQ, Lawson DE, Heizmann CW (1988) Loss of calbindin-28K immunoreactive neurones from the cortex in Alzheimer-type dementia. Brain Res 475:156-159.

Jakob H. Beckmann H (1994) Circumscribed malformation and nerve cell alterations in the entorhinal cortex of schizophrenics: pathogenetic and clinical aspects. J Neural Trans 98:83-106.

Jones RSG (1993) Entorhinal hippocampal connections: a speculative view of their function. Trends Neurosci 16:58-64.

Katayama Y, Becker DP, 'Tamura 'I', Hovda DA (1990) Massive increases in extracellular potassium and the indiscriminate release of glutamate following concussive brain injury. J Neurosurg 73:889-900.

Klagsbrun M (1989) The fibroblast growth factor family: structural and biological properties. Prog Growth Factor Res 1:207-235.
Levisohn LF, Isacson O (1991) Excitotoxic lesions of the rat entorhinal cortex: effects of selective neuronal damage on acquisition and retention of a non-spatial reference memory task. Brain Res 564:230-244.

Liu Z, D'Amore PA, Mikati M, Gatt A, Holmes GL (1993) Neuroprotective effect of chronic infusion of basic fibroblast growth factor on seizure-associated hippocampal damage. Brain Res 626:335-338.

Louis JC, Magal E, Gerdes W, Seifert W (1993) Survival-promoting and protein kinase $\mathrm{C}$-regulating roles of basic FGF for hippocampal neurons exposed to phorbol ester, glutamate and ischaemia-like conditions. Eur J Neurosci 5:1610-1621.

Mattson MP, Cheng B (1993) Growth factors protect neurons against excitotoxic/ischemic damage by stabilizing calcium homeostasis. Stroke 24:1136-1140.

Mattson MP, Rychlik B, Chu C, Christakos S (1991) Evidence for calcium-reducing and excito-protective roles for the calcium-binding protein calbindin-D28k in cultured hippocampal neurons. Neuron 6:41-51.

Mattson MP, Rydel RE, Lieberburg I, Smith-Swintosky VL (1993a) Altered calcium signaling and neuronal injury: stroke and Alzheimer's disease as examples. Ann NY Acad Sci 679:1-21.

Mattson MP, Tomaselli KJ, Rydel RE (1993b) Calcium-destabilizing and neurodegenerative effects of aggregated $\beta$-amyloid peptide are attenuated by basic FGF. Brain Res 621:35-49.

Mattson MP, Zhang Y, Bose S (1993c) Growth factors prevent mitochondrial dysfunction, loss of calcium homeostasis, and cell injury, but not ATP depletion in hippocampal neurons deprived of glucose. Fxp Neurol 121:1-13.

Mattson MP, Kumar KN, Wang H, Cheng B, Michaelis EK (1993d) Basic FGF regulates the expression of a functional $71 \mathrm{kDa}$ NMDA receptor protein that mediates calcium influx and neurotoxicity in hippocampal neurons. J Neurosci 13:4575-4588,

Michel RP, Cruz-Orive LM (1988) Application of the Cavalieri principle and vertical sections method to lung: estimation of volume and pleural surface area. J Microsc 150:117-136.

Miller RJ (1991) The control of ncuronal $\mathrm{Ca}^{2+}$ homeostasis. Prog Neurobiol 37:255-285.

Morino-Wannier P, Fujita SC, Jones EG (1992) GABAergic neuronal populations in monkey primary auditory cortex defined by co-localized calcium binding protcins and surface antigens. Exp Brain Res 88:422-432.

Mullen RJ, Buck CR, Smith AM (1992) NeuN, a neuronal specific nuclear protein in vertebrates. Development 116:201-211.

Nakata N, Kato H, Kogure K (1993) Protective effects of basic fibroblast growth factor against hippocampal neuronal damage following cerebral ischemia in the gerbil. Brain Res 605:354-356.

Nozaki K, Finklestein SP, Beal MF (1993) Basic tibroblast growth factor protects against hypoxia-ischemia and NMDA neurotoxicity in neonatal rats. J Cereb Blood Flow Metab 13:221-228.

Otto D, Unsicker K (1990) Basic FGF reverses chemical and morphological deficits in the nigrostriatal system of MPTP-treated mice. J Neurosci 10:1912-1921.

Otto D, Frotscher M, Unsicker K (1989) Basic fibroblast growth factor and nerve growth factor administered in gel foam rescue medial septal neurons after fimbria fornix transection. J Neurosci Res 22:83-91.

Peterson DA, Jones DG (1993) Determination of neuronal number and process surface area: a stereological approach to in vitro quantitation. $\mathbf{J}$ Neurosci Methods 46:107-120.

Peterson DA, Lucidi-Phillipi CA, Eagle KA, Gage FH (1994) Pcrforant path damage results in progressive neuronal death and somal atrophy in layer II of entorhinal cortex and functional impairment with increasing postdamage age. J Neurosci 14:6872-6885.

Ray J, Hogg J, Beutler AS, Takayama H, Baird A, Gage FH (1995) Expression of biologically active basic fibroblast growth factor by genetically modified rat primary skin fibroblasts. J Neurochem 64:503-513.

Ray J, Peterson DA, Schinstine M, Gage FH (1993) Proliferation, differentiation and long-term culture of primary hippocampal neurons. Pruc Nall Acad Sci USA 90:3602-3606.

Regli L, Anderson RE, Meyer FB (1994) Basic fibroblast growth factor increases cortical blood flow in vivo. Brain Res 665:155-157.

Rogers JH (1992) Immunohistochemical markers in rat cortex: colocalization of calretinin and calbindin-D28k with neuropeptides and GABA. Brain Res 587:147-157.

Rosenberg MB, Friedmann T, Robertson RC, Tuszynski M, Wolff JA, Breakefield XO, Gage FH (1988) Grafting of genetically modified 
cells to the damaged brain: restorative effects of NGF gene expression. Science 242:1575-1578.

Skaper SD, Leon A, Facci L (1993) Basic fibroblast growth factor modulates sensitivity of cultured hippocampal pyramidal neurons to glutamate cytotoxicity: interaction with ganglioside GM1. Dev Brain Res 71:1-8.

Sterio DC (1984) The unbiased estimation of number and sizes of arbitrary particles using the dissector. J Microse 134:127-136.

Takayama H, Ray J, Raymon HK, Baird A, Hogg J, Fisher LJ, Gage FH (1995) Basic fibroblast growth factor increases dopaminergic graft survival and function in a rat model of Parkinson's disease. Nature Med 1:53-58.

Toth K, Freund TF (1992) Calbindin D28k-containing nonpyramidal cells in the rat hippocampus: their immunoreactivity for GABA and projection to the medial septum. Neuroscience 49:793-805.

Tunon T, Insausti R, Ferrer I, Sobreviela T, Soriano E (1992) Parvalbumin and calbindin D-28K in the human entorhinal cortex: an immunohistochemical study. Brain Res 589:24-32.

Walicke PA (1988) Basic and acidic fibroblast growth factors have trophic effects on neurons from multiple CNS regions. J Neurosci 8:2618-2627.

Walicke PA, Baird A (1991) Internalization and processing of basic fibroblast growth factor by neurons and astrocytes. J Neurosci 11:2249-2258.
Walicke PA, Cowan WM, Ueno N, Baird A, Guillemin R (1986) Fibroblast growth factor promotes survival of dissociated hippocampal neurons and enhances neurite extension. Proc Natl Acad Sci USA 83:3012-3016.

Wiig KA, Bilkey DK (1994) The effects of perirhinal cortical lesions on spatial reference memory in the rat. Behav Brain Res 63:101-109.

Witter MP (1993) Organization of the entorhinal-hippocampal system: a review of current anatomical data. Hippocampus 3:33-44.

Yamada K, Kinoshita A, Kohmura E, Sakaguchi T, Taguchi J, Kataoka K, Hayakawa T (1991) Basic fibroblast growth factor prevents thalamic degeneration after cortical infarction. J Cereb Blood Flow Metab 11:472-478.

Yamada T, Mcgeer PL, Baimbridge KG, Mcgeer EG (1990) Relative sparing in Parkinson's disease of substantia nigra dopamine neurons containing calbindin-D28K. Brain Res 526:303-307.

Yee WM, Frim DM, Isacson O (1993) Relationships between stress protein induction and NMDA-mediated neuronal death in the entorhinal cortex. Exp Brain Res 94:193-202.

Zhang Y, Tatsuno T, Carney JM, Mattson MP (1993) Basic FGF, NGF, and IGFs protect hippocampal and cortical neurons against ironinduced degeneration. J Cereb Blood Flow Metab 13:378-388. 